Boston University School of Law

Scholarly Commons at Boston University School of Law

Faculty Scholarship

$5-2020$

\title{
Telehealth for an Aging Population: How Can Law Influence Adoption Among Providers, Payors, and Patients?
}

Tara Sklar

Christopher Robertson

Boston University School of Law

Follow this and additional works at: https://scholarship.law.bu.edu/faculty_scholarship

Part of the Elder Law Commons, and the Health Law and Policy Commons

\section{Recommended Citation}

Tara Sklar \& Christopher Robertson, Telehealth for an Aging Population: How Can Law Influence Adoption Among Providers, Payors, and Patients?, 46 American Journal of Law \& Medicine 311 (2020).

Available at: https://scholarship.law.bu.edu/faculty_scholarship/966

This Article is brought to you for free and open access by Scholarly Commons at Boston University School of Law. It has been accepted for inclusion in Faculty Scholarship by an authorized administrator of Scholarly Commons at Boston University School of Law. For more information, please contact lawlessa@bu.edu. 


\title{
Telehealth for an Aging Population: How Can Law Influence Adoption Among Providers, Payors, and Patients?
}

\author{
Tara Sklar ${ }^{\dagger}$ and Christopher T. Robertson ${ }^{\dagger \dagger}$
}

\begin{abstract}
Telehealth continues to experience substantial investment, innovation, and unprecedented growth. However, telehealth has been slow to transform healthcare. Recent developments in telehealth technologies suggest great potential for chronic care management, mental health services, and care delivery in the home-all of which should be particularly impactful for an aging population with physical and cognitive limitations. While this alignment of technological capacity and market demand is promising, legal barriers remain for telehealth operators to scale up across large geographic areas. To better understand how federal and state law can be reformed to enable greater telehealth utilization, we review and extract lessons from (1) establishment of a healthcare relationship, (2) state licensure laws, and (3) reimbursement. We analyze these areas because of the legal ambiguities or inconsistencies they raise depending on the state, which seem to be hampering telehealth growth without necessarily improving quality of care. We propose several solutions for a more unified approach to telehealth regulation that incorporate core bioethics principles of doctor-patient relationship, competence, patient autonomy, as well as population-wide questions of resource allocation and access. Lawmakers should clarify that healthcare relationships may be established outside of in-person meetings, align licensure laws via an interstate compact or federal preemption, and expand Centers for Medicare and Medicaid plans to reimburse telehealth delivery in the home.
\end{abstract}

\section{INTRODUCTION}

The term "telehealth" refers to the practice of evaluating, diagnosing, and treating patients at a distance using telecommunications technology. ${ }^{1}$ By 2012 , half of all U.S. hospitals were reporting that they had telehealth programs, and by 2018 that number grew to nearly $90 \%$ of healthcare organizations using or planning to implement

\footnotetext{
†rofessor of Health Law; Director, Health Law \& Policy Program, James E. Rogers College of Law, University of Arizona.

†rofessor of Law; Associate Dean for Research \& Innovation, James E. Rogers College of Law, University of Arizona. The authors appreciate the assistance of University of Arizona research librarians, led by Maureen Garmon, and research assistants Ellen Stark and Kelleen Rae. Bert Skye provided administrative support. Initial work on this topic was done while serving as the reporter for the Health Law Monitoring Committee of the Uniform Law Commission. Opinions are the authors' own.

${ }^{1}$ What is Telemedicine, CHIRON HEALTH, https://chironhealth.com/telemedicine/what-istelemedicine/ [https://perma.cc/PAU3-7S3X] (last visited Mar. 20, 2020).
} 
telehealth platforms. ${ }^{2}$ Telehealth is sometimes defined expansively to include, "mak[ing] online appointments, view[ing] test results through a website, ask[ing] medical questions through email, and communicat[ing] with a provider . . . on the phone, via live video, using live text chat, via a mobile phone text message, and using a mobile app." ${ }^{\prime 3}$ In practice, synchronous videoconferencing is the gold standard, but storeand-forward imaging and wireless data communications between devices are also widely used. ${ }^{4}$

The traditional policy priority for telehealth is to increase access to healthcare for remote patients, especially in rural areas. ${ }^{5}$ Rural and remote populations were early adopters of telehealth, largely to mitigate travel distance, time, and appointment delay. ${ }^{6}$ Yet research in the field suggests that adoption is still lagging, due to limited internet connectivity and lack of broadband in particular. ${ }^{7}$ Major federal funding infusions seek to improve broadband, but there are still areas of the country, called "digital deserts," affecting approximately 24 million people (including 1.4 million on Tribal lands). ${ }^{8}$ The Federal Communications Commission created a task force, called Connect2Health, which maps gaps in broadband and telehealth availability along with health measures. ${ }^{9}$

Beyond rural and remote populations, there is also a growing effort to provide telehealth for all patients at the times and places of their choosing. ${ }^{10}$ A recent national study found that the strongest predictor for telehealth utilization is not geographic distance from a provider; rather, it is difficulty leaving the home due physical and mental limitations. ${ }^{11}$ Currently, upwards of 1.8 million older adults in the United States are partially or completely homebound, due to chronic illnesses and functional limitations. ${ }^{12}$ In addition to the challenge of care delivery, homebound older adults lack exposure to the world outside the home and often, with that, regular human contact. Social isolation and loneliness are more common among older adults and have been linked to increased health risks and illness burden, and this phenomenon is increasingly referred to as a loneliness epidemic across the United States..$^{13}$ Telehealth may be part of the solution,

\footnotetext{
2Julia Adler-Milstein et al., Telehealth Among US Hospitals: Several Factors, Including State Reimbursement and Licensure Policies, Influence Adoption, 33 HEALTH AFF. 207, 207-15 (2014).

${ }^{3}$ Jeongyoung Park et al., Are State Telehealth Policies Associated with the Use of Telehealth Services Among Underserved Populations?, 37 HEALTH AFF. 2060, 2061 (2018).

${ }^{4} \mathrm{~J}$ ohn Craig \& Victor Patterson, Introduction to the Practice of Telemedicine, $11 \mathrm{~J}$. TELEMEDICINE \& TELECARE 3, 4 (2005).

${ }^{5}$ Why are Telemedicine and Telehealth So Important in Our Healthcare System?, CAL. TELEHEALTH RES.CTR., http://www.caltrc.org/telehealth/why-are-telemedicine-and-telehealth-so-importantin-our-healthcare-system/ [https:/perma.cc/2GZQ-4L4W] (last visited Mar. 20, 2020).

${ }^{6}$ Rashid L. Bashshur, Telemedicine and Health Care, 8 TELEMEDICINE J. \& E-HEALTH 5, 7 (2002). ${ }^{7}$ See Brittney Crock Bauerly et al., Broadband Access as a Public Health Issue: The Role of Law in Expanding Broadband Access and Connecting Underserved Communities for Better Health Outcomes, $47 \mathrm{~J}$. LAW, MED. \& ETHICS 39, 40 (2019) ("Despite telehealth's great potential to improve healthcare access, the promise of telehealth is stymied by the lack of reliable broadband coverage in many parts of the United States.").

${ }^{8} I d$. at 39

9Mapping Broadband Health in America, FED. COMMC'NS COMM'N https://www.fcc.gov/health/maps [https://perma.cc/8UFA-9BXL] (last visited Mar. 20, 2020).

${ }^{10}$ See Ilene Warner, Telemedicine in Home Health Care: The Current Status of Practice, 10 HOME HeAlth CARE MgMT. \& PRAC. 62, 62-63 (Feb. 1998) (discussing the benefits of telemedicine without limitations on locale).

${ }^{11}$ See Park et al., supra note 3, at 2066.

${ }^{12}$ Katherine A Ornstein et al., Epidemiology of the Homebound Population in the United States, 175 J. AM. MED. ASS'N: InTERNAL MED. 1180, 1184 (2015).

${ }^{13}$ Social Isolation, Loneliness in Older People Pose Health Risks, NAT'L INST. ON AGING (Apr. 23 , 2019), https://www.nia.nih.gov/news/social-isolation-loneliness-older-people-pose-health-risks [https://perma.cc/LX4N-A828].
} 
or it may turn out to be a poor substitute for in-person human contact, leading to less autonomy and greater neglect, isolation, and helplessness. ${ }^{14}$

Telehealth could curb the skyrocketing costs of providing chronic and preventative care and perhaps even address social determinants of health, the primary upstream driver of costs and health outcomes..$^{15}$ Telehealth may reduce healthcare expenditures for employers, insurers, and patients by substituting inexpensive virtual visits in place of costly in-person visits to emergency departments or doctors' offices. ${ }^{16}$ Conversely, telehealth could increase costs if patients use telehealth services in addition to in-person visits, not as a substitute. ${ }^{17}$ Telehealth has also been shown to sometimes provide beneficial health outcomes with no net change in costs. ${ }^{18}$ Telehealth's cost profile may depend on varying state laws across the country regarding (1) the establishment of a healthcare relationship, (2) provider licensure laws, and (3) reimbursement. These variations may shape behaviors of doctors and patients, create incidental compliance costs for telehealth operators, and hinder telehealth operators' ability to leverage resources across state lines for efficient scalability. ${ }^{19}$

This Article is organized into two Parts. Part I describes the important fit between older adults' healthcare needs and telehealth's capabilities. Part II analyzes three broad areas of conflicting state laws that impact telehealth scalability and discusses ethical considerations around reforming these laws. A brief conclusion suggests the importance of reforming laws to positively influence telehealth cross-border practice and delivery in the home, to optimally achieve greater access, improve health outcomes, and lower costs.

\section{TELEHEALTH FOR AN AGING POPULATION}

We focus on older patients for three reasons. First, older adults are living longer (21 years on average post-age 65). ${ }^{20}$ They are an increasingly large portion of the population (projected to outnumber children by the year 2035), ${ }^{21}$ and they drive a disproportionate share of healthcare expenditures (consuming about one in three of all healthcare dollars). ${ }^{22}$

Medicare, the primary source of health insurance for older adults, covers 56 million beneficiaries. ${ }^{23}$ By 2030, there will be 79 million Medicare beneficiaries, or a

${ }^{14}$ Tara Sklar \& Kathryn Huber, Frailty and Big Data: The Two Sides of Technology in 'Personalised' Elder Care, in DATA DRIVEN PERSONALISATION AND THE LAW: A PRIMER (Jacob Eisler \& Uta Kohl eds.) (forthcoming 2020) (on file with authors).

${ }^{15}$ Dawn E. Alley et al., Accountable Health Communities - Addressing Social Needs Through Medicare and Medicaid, 374 N. ENGL. J. MED. 8, 8 (2016).

${ }^{16}$ Lori Uscher-Pines et al., Access and Quality of Care in Direct-to-Consumer Telemedicine, 22 TELEMEDICINE J. \& E-HEALTH 282, 282 (2016).

${ }^{17}$ See J. Scott Ashwood et al., Direct-To-Consumer Telehealth May Increase Access to Care but Does Not Decrease Spending, 36 HEALth AFF. 485, 489-90 (2017).

${ }^{18}$ Donna Lee Armaignac et al., Impact of Telemedicine on Mortality, Length of Stay, and Cost Among Patients in Progressive Care Units, 46 CRITICAL CARE MED. 728, 734 (2018).

${ }^{19}$ Joseph Kvedar et al., Connected Health: A Review of Technologies and Strategies to Improve Patient Care with Telemedicine and Telehealth, 33 HEALTH AFF. 194, 198 (2014).

${ }^{20}$ See Geoffrey F. Joyce et al., The Lifetime Burden of Chronic Disease Among the Elderly, 24 HEALTH AFF. 1,8 (2005).

${ }^{21}$ Jonathan Vespa, The U.S. Joins Other Countries With Large Aging Populations, U.S. CENSUS BUREAU (Mar. 15, 2019), http://hispanicad.com/agency/research/us-joins-other-countries-large-agingpopulations, [https://perma.cc/4BWQ-V7GZ].

${ }^{22}$ David Lassman et al., US Health Spending Trends by Age and Gender: Selected Years 2002-10, 33 HeALth AFF. 815, 821 (2014).

${ }^{23}$ Cathy Schoen et al., Medicare Beneficiaries' High Out-of-Pocket Costs: Cost Burdens by Income 
fifth of the U.S. population. ${ }^{24}$ To be financially sustainable, this projected growth will likely require revision of benefits and could result in increasing out-of-pocket costs for beneficiaries. ${ }^{25}$ If costs are out of proportion to beneficiaries' ability to pay, then the sicker, poorer patients may go without care, reduce adherence to their medications, or increase emergency room visits. ${ }^{26}$ The current and projected healthcare needs for older adults require a cost-effective solution.

Second, older adults have particularly prevalent needs for management of chronic conditions and mental health care, which may be the forte of telehealth. Approximately $80 \%$ of older adults have at least one chronic condition, and $77 \%$ have at least two. ${ }^{27}$ Telehealth can improve medication adherence through routine monitoring, integration of medical tests, and adjustment of medications, if needed. ${ }^{28}$ At least one study found a reduction in healthcare expenditures via home monitoring programs for chronic conditions that successfully prevented hospital visits and readmissions. ${ }^{29}$

Similarly, for mental healthcare, numerous randomized trials found that for Medicare beneficiaries, telehealth can be superior to in-person care. ${ }^{30}$ The Institute of Medicine and other organizations report that one in five older adults suffer from mental illness, substance abuse, or both, at a time when there is a shrinking number of mental health providers ${ }^{31}$ Moreover, one-fifth of older adults may be an underestimate as mental health needs are often undiagnosed. ${ }^{32}$ Many physicians are not trained to recognize mental illness among older adults, and research shows that it manifests differently than younger adults. ${ }^{33}$ For example, older adults are less likely to report psychological or emotional feelings of sadness, and more likely to complain of physical symptoms, such as body aches, sleeplessness, and poor appetite. ${ }^{34}$ They are also more likely to have mental health disorders that exist alongside complicated physical illnesses (e.g., multiple chronic conditions), which can overshadow symptoms of a mental health disorder ${ }^{35}$ Relatedly, older adults with mental illness have higher rates of hospitalization and emergency department visits than people with physical illnesses alone, and one

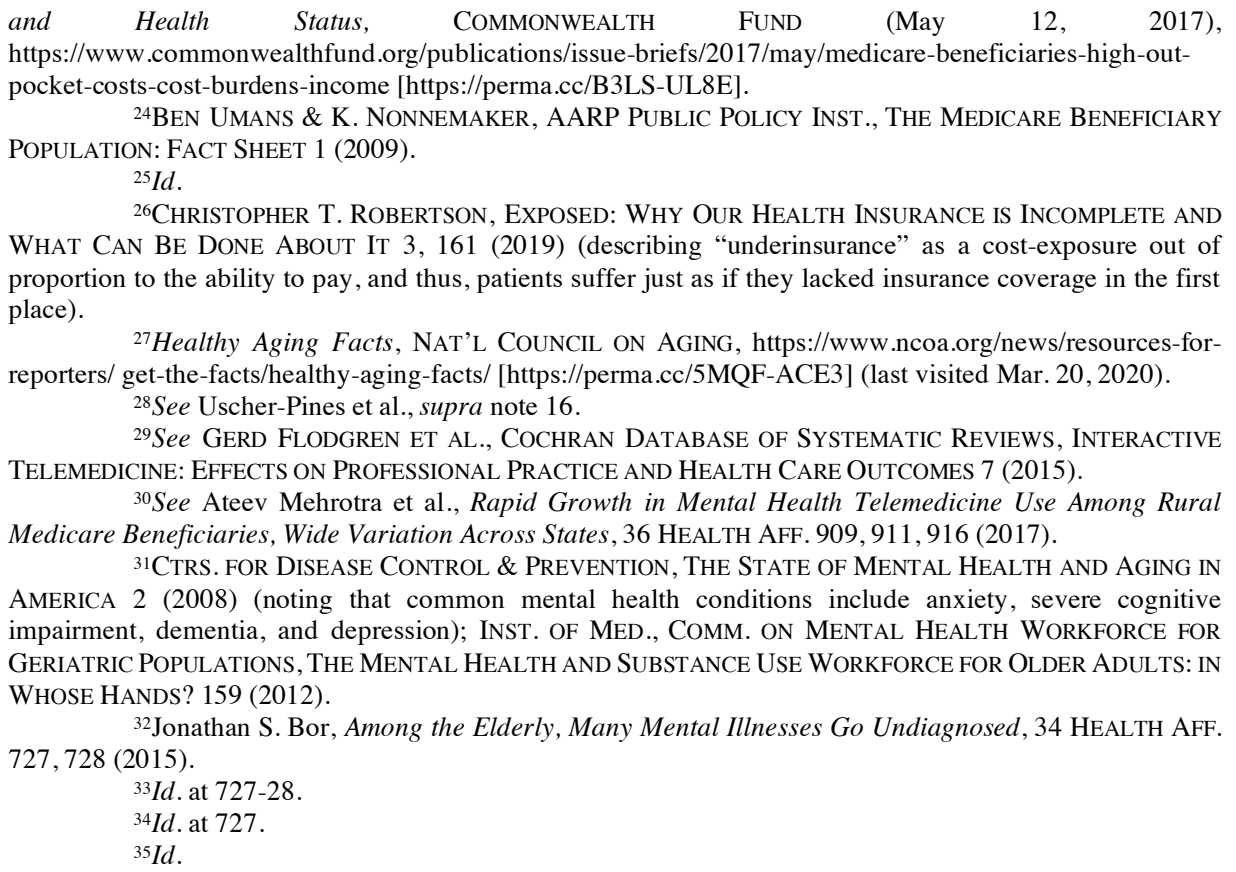

${ }^{27}$ Healthy Aging Facts, NAT'L COUNCIL ON AGING, https://www.ncoa.org/news/resources-forreporters/ get-the-facts/healthy-aging-facts/ [https://perma.cc/5MQF-ACE3] (last visited Mar. 20, 2020).

${ }^{28}$ See Uscher-Pines et al., supra note 16.

${ }^{29}$ See GeRD FlodGREN ET AL., COCHRAN DATABASE OF SySTEMATIC REVIEWS, INTERACTIVE TElEmEdicine: EFFECTS On PROFESSIONAL PRACTICE AND HEALTH CARE OUTCOMES 7 (2015).

${ }^{30}$ See Ateev Mehrotra et al., Rapid Growth in Mental Health Telemedicine Use Among Rural Medicare Beneficiaries, Wide Variation Across States, 36 HEALTH AFF. 909, 911, 916 (2017).

${ }^{31}$ CTRS. For Disease Control \& PREVEntion, The State of MENTAL HeAlth AND AgING IN AMERICA 2 (2008) (noting that common mental health conditions include anxiety, severe cognitive impairment, dementia, and depression); InST. OF MED., COMM. ON MENTAL HEALTH WORKFORCE FOR Geriatric Populations, The Mental HeAlth AND Substance UsE WORKFORCE FOR OLDER ADULTS: IN WHOSE HANDS? 159 (2012).

32Jonathan S. Bor, Among the Elderly, Many Mental Illnesses Go Undiagnosed, 34 HEALTH AFF. 727, 728 (2015).

${ }^{33} I d$. at $727-28$.

${ }^{34}$ Id . at 727.

${ }^{35} \mathrm{Id}$. 
study found that these increased visits also increased per-person costs by as much as $200 \% .{ }^{36}$ Older adults are also a growing part of the opioid epidemic, which continues to claim thousands of deaths annually. ${ }^{37}$

Accordingly the Centers for Medicare \& Medicaid Services ("CMS") issued a rule, coming into effect in 2020, to relax geographic and originating site requirements specifically for Medicare Advantage ("MA") plans. ${ }^{38}$ Going forward, MA plans will be able to reimburse for telehealth services received directly in the home, irrespective of whether the beneficiary lives in a rural or urban area. ${ }^{39}$ As distinct from traditional Medicare, MA allows beneficiaries the option to receive their benefits via private health insurers, which may offer lower cost exposures or additional benefits. ${ }^{40}$ Currently, 20.4 million older adults have opted for MA and the annual growth rate at eight percent is projected to continue..$^{41} \mathrm{MA}$ plans are eager to incorporate telehealth delivery in the home as an additional benefit, as it is uniquely suited to manage routine care around chronic conditions as well as other health conditions (e.g., mental health) that disproportionately impact older adults..$^{42}$

The third reason to focus on older adults is that they have been, so far, especially unlikely to actually use telehealth technologies. A 2018 study shows that the odds of using live video communications with a doctor were 16 times higher for those aged 25-44 than for those over age 65. ${ }^{43}$ Nonetheless, almost half of Medicare beneficiaries expressed willingness to use such a video call, while only one percent had actually done so..$^{44}$

Another survey found that a mere four percent of older adults had a telehealth visit in the past year. ${ }^{45}$ As part of this survey, older adults described some reasons regarding their reluctance to embrace telehealth and reported not feeling as "connected" to the doctor and difficulty in communicating. ${ }^{46}$ Difficulty "seeing or hearing" the doctor could lead to a suboptimal diagnosis and treatment plan. ${ }^{47}$ This concern supports some researchers' claims that there may be real consequences to "the absence of laying on the hands" in terms of weakening an accurate diagnosis. ${ }^{48}$

\footnotetext{
${ }^{36}$ Stephen J. Bartels \& John A. Naslund, The Underside of the Silver Tsunami-Older Adults and Mental Health Care, 368 N. ENGL. J. MED. 493, 493 (2013).

${ }^{37}$ Opioid Overdose: Drug Overdose Deaths, CTRS. FOR DisEASE CONTROL \& PREVENTION (June 27, 2019), https://www.cdc.gov/drugoverdose/data/statedeaths.html [https://perma.cc/BYP4-RX4C].

${ }^{38}$ Press Release, Ctrs. for Medicare \& Medicaid Servs., CMS Finalizes Polices to Bring Innovative Telehealth Benefit to Medicare Advantage (Apr. 5, 2019), https://www.cms.gov/newsroom/pressreleases/cms-finalizes-policies-bring-innovative-telehealth-benefit-medicare-advantage [https://perma.cc/NWW5-PR5T] [hereinafter CMS Finalizes Polices to Bring Telehealth to Medicare Advantage].

${ }^{39} I d$.

${ }^{40}$ Gretchen Jacobson et al., A Dozen Facts About Medicare Advantage in 2019, KAISER FAMILY FounD. (June 6, 2019), https://www.kff.org/medicare/issue-brief/a-dozen-facts-about-medicare-advantagein-2019 [https://perma.cc/H99T-QZU4].

${ }^{41} I d$.

${ }^{42}$ Ateev Mehrotra, RAND Office of External Aff., Testimony before the House Energy and Commerce Committee's Subcommittee on Health (May 1, 2014) (addressing the advantages and disadvantages of expanding the use of telehealth).

${ }^{43}$ Park et al., supra note 3, at 2063.

${ }^{44} I d$.

45Jane Sarasohn-Kahn, The Promise of Telehealth for Older People - the U-M National Poll on Healthy Aging, HEALTHPOPULI (Oct. 3, 2019), https://www.healthpopuli.com/2019/10/03/the-promise-oftelehealth-for-older-people/ [https://perma.cc/6TKK-7Y3P]

${ }^{46}$ Id .

${ }^{47}$ EDWARd A. MilLER, NufFIELD COUNCIL WORKING PARTY, TELEMEDICINE AND THE PROVIDERPATIENT RELATIONSHIP: WHAT WE KNOW SO FAR 16-17 (2010).

${ }^{48} I d$. at 20.
} 
If these concerns can be addressed, the potential for growth is huge. One novel approach is to involve a third party, such as a home health aide, especially with initial visits. ${ }^{49}$ This individual could function as a bridge to compensate for the lack of physical contact and support communication between the doctor and patient, including checking for patients' understanding of the medical care provided and treatment plan. Such a personal visit may also identify pertinent information, such as smells of mold, rotting food, or urine, which could be indicators of cognitive or physical decline that may be missed via solely telehealth care. This sort of approach requires attention to provider training, quality concerns, and lack of awareness which are all non-legal factors that may impinge utilization. ${ }^{50}$

\section{LEGAL BARRIERS AND SOLUTIONS FOR SCALABILITY}

Although the practice of medicine has traditionally been viewed as within the purview of state regulation, ${ }^{51}$ telehealth across state borders, or even merely using the channels and instrumentalities of commerce (the internet), implicates a potential federal role. ${ }^{52}$ Nonetheless, the federal government has largely been silent, other than funding grants to build infrastructure and demonstration projects, ${ }^{53}$ and in resolving reimbursement by federal payors. ${ }^{54}$ Congress has also considered a range of legislation, but it tends to either focus on federal reimbursement or make mere recommendations to states. ${ }^{55}$

The Federal Trade Commission ("FTC") has been influential in sending letters and issuing reports, to ensure that state legislation and litigation do not undermine competitiveness of healthcare, by creating special restrictions not applicable to local providers. ${ }^{56}$ The FTC has stated that broadly applicable safeguards, such as competency and the standard of care, should suffice for doctors, regardless of whether they are operating remotely or locally. ${ }^{57}$ These federal efforts suggest that blatant protectionism for local providers will not be tolerated..$^{58}$

Inaction by the federal government has left the states to legislate, but the laws vary wildly, creating uncertainty around cross-border practice. One study examined the impact of state telehealth policies on the use of telehealth in a dataset covering 20132016, exploring whether less restrictive state policies may lead to increased utilization. ${ }^{59}$

\footnotetext{
${ }^{49}$ Theodosia Stavroulaki, Mind the Gap: Antitrust, Health Disparities and Telemedicine, 45 AM. J.L. \& MED. 171, 179-89 (2019).

${ }^{50}$ Ctr. For Connected Health Policy, Telehealth Private Payer Laws: Impact and ISSUES 15 (2017) [hereinafter TELEHEALTH PRIVATE PAYER LAWS]. 503 (2000).

${ }^{51}$ See generally Kevin Outterson, Health Care, Technology, and Federalism, 103 W. VA. L. REV.

${ }^{52}$ See generally Amar Gupta \& Deth Sao, The Constitutionality of Current Legal Barriers to Telemedicine in the United States: Analysis and Future Directions of Its Relationship to National and International Health Care Reform, 21 HEALTH MATRIX: J.L. \& MED. 385 (2011).

${ }^{53}$ See Inst. OF Med., Div. OF Health CARE SERvs. Telemedicine: A Guide To Assessing TElECOMMUNiCATIONS For HeAlth CARE 229-38 (1996).

${ }^{54}$ See 42 C.F.R. $\$ 410.78$ (2011) (defining when Medicare Part B will reimburse telehealth services)

${ }^{55}$ See, e.g., Telehealth Modernization Act of 2015, H.R. 691, 114th Cong. (2015) (promoting the provision of telehealth by establishing federal standards for telehealth).

${ }^{56}$ The Federal Trade Commission and Professional Licensure Boards, NAT'L TELEHEALTH POLICY RES. CTR., https://www.cchpca.org/telehealth-policy/federal-trade-commission-and-professional-licensureboards [https://YH54-EQDF] (last visited Mar. 20, 2020).

${ }^{57} I d$.

${ }^{58}$ See id.

${ }^{59}$ Park et al., supra note 3, at 2060-62.
} 
The study found that the odds of using live video communication were 1.338 times higher among respondents in states with less restrictive policies.$^{60}$ Nonetheless, the study lacked statistical power to confirm that the difference was real. ${ }^{61}$

This section focuses on how variations in state laws in three key areas limit the practice of interstate telehealth. We describe the current laws, including benefits that they may achieve, repercussions if they were to be modified, and alternative approaches.

\section{A. Establishment of A HealthCARe Relationship}

Legal and ethical analyses have long turned on whether a doctor-patient relationship has been established, but the particular modality of communication has not been of primary concern. In-person visits can facilitate the development of trust and more granular information exchange between a doctor and patient, potentially revealing counter-indications and serving broader healthcare goals (e.g., checking for vaccination status, cancer screening, or substance use) ${ }^{62}$ In contrast, telehealth could allow a healthcare provider to have a very superficial relationship with a patient. For extreme examples, a patient may merely check off symptoms on a webform or send an email. ${ }^{63}$ In some ways, this is the epitome of efficiency-if a patient needs a statin, why not make it as simple and easy as possible to get that prescription written? On the other hand, unscrupulous doctors could exploit such minimal contacts to generate easy billings or patients may exploit them trying to get narcotics. ${ }^{64}$ More generally, some claim this technology interferes with the development of a personal doctor-patient relationship by being "dehumanizing, dissocializing and depersonalizing." 65

The American Medical Association ("AMA") has promulgated an opinion that does not fully embrace telemedicine, deeming even synchronous video as insufficient to establish a doctor-patient relationship. ${ }^{66}$ Instead, subject to certain exceptions, the doctor-patient relationship should be established through an in-person visit, or through consultation with a doctor who has an established relationship, or in other ways specified in specialist national practice guidelines. ${ }^{67}$ This opinion reflects a presumption that in-person interactions should remain the baseline.

The AMA produced a 50-state survey on this question, which clearly illustrates the discrepancies between state laws and the resulting difficulties for telehealth scalability. Some states (e.g., Alabama) broadly track the AMA's suggestion and others (e.g., Idaho), allow a relationship to be established via telehealth, as long as the doctor and patient interact via two-way audio and video ${ }^{68}$ Some states (e.g. Arkansas) target

${ }^{60} I d$. at 2064-65.

${ }^{61} I d$. at 2065.

${ }^{62}$ See generally Zelda Di Blasi et al.,Influence of Context Effects on Health Outcomes: A Systematic Review, 357 LANCET 757 (2001) (explicating both emotional and informational aspects of the doctor-patient relationship).

${ }^{63}$ See, e.g., Telehealth Services in San Diego, SCRIPPS (Feb. 24, 2020), https://www.scripps.org/news_items/6893-telehealth-services-in-san-diego [https://perma.cc/7LBL-KVDV] (offering online health questionnaires that providers subsequently review and prescribe a written care plan tailored to the patient within 30 minutes).

${ }^{64}$ Press Release, U.S. Dep't of Justice (Apr. 9, 2019), https://www.justice.gov/opa/pr/federalindictments-and-law-enforcement-actions-one-largest-health-care-fraud-schemes [https://perma.cc/B882CK62].

${ }^{65}$ See MILLER, supra note 47 , at 17.

${ }^{66}$ See AM. Med. Ass'N, COVERAge OF AND PAYMENT FOR TELEMEDICINE 1 (2015).

${ }^{67} I d$. at $1-2$.

${ }^{68}$ AM. MED. Ass'N, 50-STATE SURVEY: Establishment OF A PATIENT-PHYSiCIAN RelationSHIP Via Telemedicine 1-2 (2018) [hereinafter 50-State SuRVey: Patient-Physician Relationship Via TELEMED] 
and proscribe the use of web-forms as the sole basis for treating or prescribing. ${ }^{69}$ In contrast, a Utah law for hormonal contraceptives provides for asynchronous prescribing through an "online branching questionnaire" that has been approved by the Board of Pharmacy. ${ }^{70}$ Nonetheless, like many states, Utah's medical board has held that an inperson or synchronous examination must occur prior to any telemedicine services being provided. ${ }^{71}$

Tennessee is an outlier in that it deems that a physician-patient relationship is established "when a physician serves a patient's medical needs whether or not there has been an encounter in-person between the physician and patient." 72 Tennessee's broader approach reflects the ethical principles of autonomy and consent to establish a physicianpatient relationship, rather than relying on a formal distinction of modality whether it is through telehealth, in-person, or a future technology.

There are population-wide ethical considerations in setting the right rule for relationship-establishment. A requirement of in-person visits could increase costs, reduce access, and potentially undermine innovation. If a law requires an in-person visit or even a particularly robust telehealth visit (e.g., synchronous video), some patients may receive no care at all. ${ }^{73}$ If such laws are motivated more by doctor protectionism, rather than by bona fide concerns for patient welfare, then they may simply increase healthcare costs by reducing competition and efficiency.

Malpractice law also interacts with this question of how a relationship is established, although there are few cases directly on telemedicine.$^{74}$ Historically, tort law required that physicians behave according to customary practices in their field. ${ }^{75}$ Thus, even if a telehealth visit were reasonable under the circumstances, a physician might be found liable if his or her peers were not customarily using this modality at a particular point in time. More than three decades ago, courts recognized that a telephone call could initiate a doctor-patient relationship. ${ }^{76}$ Generally, some courts have begun to embrace an objective reasonable care standard, applicable to other tortfeasors. ${ }^{77}$ This approach may be more functional and flexible, tracking the practical costs and benefits

${ }^{69}$ ARK. CODE ANN. § 17-80-403 (2019).

${ }^{70}$ UtAH CODE ANN. § 58-32-101 (LexisNexis 2019); UtAH AdMIN. CODE r. 156-83-306 (2019).

${ }^{71}$ UTAH CODE ANN. \$§ 26-60-101, 26-60-102, 26-60-103 (LexisNexis 2019); UTAH ADMIN. CODE r. 156-1-602(6) (2019).

${ }^{72}$ TENN. COMP. R. \& REGS. 0880-02-.16 (2017).

${ }^{73}$ Nicole Lewis, Telehealth Helps Close Health Care Disparity Gap in Rural Areas, Ass'N OF AM. MED. Colls. (Dec. 5, 2016), https://www.aamc.org/news-insights/telehealth-helps-close-health-caredisparity-gap-rural-areas [https://perma.cc/T67G-NVAS] (noting that rural areas would be better served with the provision of telehealth services).

${ }^{74}$ See, e.g., Allen v. Shawney, No. 11-10942, 2014 WL 1089618, at*1 (E.D. Mich. Mar. 18, 2014) (claiming deliberate indifference to medical needs constitutes a violation of patient Eighth Amendment rights). See generally Patricia C. Kuszler, Telemedicine and Integrated Health Care Delivery: Compounding Malpractice Liability, 25 AM. J.L. \& MED. 297, 297-326 (1999). Pro se prison cases are the exception.

${ }^{75}$ See Perry v. Anonymous Physician 1, 25 N.E.3d 103, 107 (Ind. Ct. App. 2014); Dolezal v. Goode, 433 N.E.2d 828, 831 (Ind.Ct.App.1982). "In the usual negligence action the defendant's conduct is judged against what a reasonable man would do under the circumstances. But the determination in a medical malpractice case whether a physician's conduct fell below the legally prescribed standard of care involves questions of science and professional judgment that are outside the realm of the layperson. That is why, in an action for medical malpractice, whether the defendant used suitable professional skill must generally be proven by expert testimony, usually that of other physicians." Perry, 25 N.E.3d at 107(citations omitted).

${ }^{76}$ Bienz v. Central Suffolk Hospital, 557 N.Y.S.2d 139, 139-40 (1990).

${ }^{77}$ See e.g., Vassos v. Roussalis, 658 P.2d 1284, 1288 (Wyo. 1983) (the standard of care was not the skill, diligence, knowledge, means, and methods "ordinarily" or "generally" or "customarily" exercised or applied, but rather are those that are "reasonably" exercised or applied.). See generally 1 STEVEN E. PEGALIS, AMERICAN LAW OF MEDICAL MALPRACTICE $\$ 3.3$ (3d.ed. 2019) (explaining how to measure reasonable care, custom, and practice in the medical profession in the common law context). 
of a particular mechanism for establishing a relationship, and differences in circumstances (e.g., statins versus narcotics).$^{78}$

For patients who cannot leave their homes without substantial difficulty, and especially in areas where there is a shortage of licensed providers, an in-person visit with a doctor seems like a particularly onerous way to establish a healthcare relationship. In many such cases, the alternative may be no care at all. Rather than such a broad-brush policy, a more forward-looking approach would be to focus on individual situations where an in-person physical exam is essential. Following the development of tort law similarly, the appropriateness of a particular modality varies case by case. One might suppose that this issue is best resolved by a general "reasonable care" tort law standard, ensuring that doctors use whatever modality may be appropriate given the circumstances.

To be sure, there are legitimate quality concerns. For example, studies have found that, when doctors do not have in-person contact with a patient, they tend to be more likely to overprescribe medicines, including antibiotics. ${ }^{79}$ Conversely, a study that scanned over 3,000 articles published from 2004-2018 found that generally telehealth services were equivalent to in-person care. ${ }^{80}$

The rub is that, if an in-person visit is considered essential to guarantee quality care, then that negates the potential of telehealth to be a genuine substitute, and accordingly increase access and decrease costs. Quality and safety checks are equally necessary for telehealth as for in-person care.

\section{B. LICENSURE OF PROVIDERS}

Generally, medical professionals must be licensed by state authorities in every jurisdiction in which they wish to practice-they must have the requisite test score, pay the required fees, and wait for approval. ${ }^{81}$ This system of state licensure of healthcare providers is another barrier to interstate growth of telehealth. ${ }^{82}$

Each state has its own medical licensing authority, which sets its own rules and requires passing an examination. ${ }^{83}$ There are several widely accepted licensing examinations that need only be taken once to fulfill licensing requirements in most states. The United States Medical Licensing Examination, for example, is accepted in all U.S. states, though the passing score required varies ${ }^{84}$ The application for licensure goes to the state medical boards and, pending no abnormal background or concerns, is

${ }^{78}$ See ReSTATEMENT (THIRD) OF TORTS: PHYSICAL \& EMOTIONAL HARM $\S 6 \mathrm{cmt}$. (d) (AM. LAW INST. 2019) (advising consideration of the expense of a precaution against its likelihood of reducing harm of a given severity); see also United States v. Carroll Towing Co., 159 F. 2d 169, 173 (2d. Cir. 1947) (describing such a burden-probability-liability calculus); Kuszler, supra note 74, at 308 (arguing that "telemedicine presents the opportunity for the courts to recast the physician/provider-patient relationship and the duties that flow from it more flexibly").

${ }^{79}$ See Lori Uscher-Pines et al., Antibiotic Prescribing for Acute Respiratory Infections in Directto-Consumer Telehealth Visits, 175 J. AM. MED. Ass'N: INTERNAL MED. 1234, 1234-35 (2015).

${ }^{80}$ See Erin Shigekawa et al., The Current State of Telehealth Evidence: A Rapid Review, 37 HEALTH AFF. 1975, 1975-76 (2018).

${ }^{81}$ United States Medical Licensure Requirements, U.S. MED. LiCENSING EXAMINATION, https://www.usmle-courses.eu/united-states-medical-licensure-requirements/ [https://perma.cc/2XSBPKLM] (last visited Mar. 20, 2020).

${ }^{82}$ See generally Wynter K. Miller, Note, Trust and Antitrust: State-Based Restrictions in Telemedicine, 50 U.C. DAVIS L. REV. 1807 (2017).

${ }^{83}$ Who is USMLE?, U.S. MED. LICENSING EXAMINATION, https://www.usmle.org/about/ [https://perma.cc/ZZR9-CSJX] (last visited Mar. 20, 2020).

${ }^{84}$ Obtaining a Medical License, AM. MED. Ass'N, https://www.ama-assn.org /education/obtainingmedical-license [https://perma.cc/K5LJ-CNHR] (last visited Mar. 20, 2020). 
typically granted in approximately 60 days. ${ }^{85}$

The traditional rule has been that the law of the patient's location applies. ${ }^{86}$ Therefore, if a doctor is licensed in California but is providing telemedicine services to a patient in ten other states, then the doctor is subject to all of those states' licensing laws and standards of care. ${ }^{87}$ The simplest and most impactful change would be to flip this rule, so that the physician's location is essential for licensure. This model has been used in other domains, but raises concerns about a "race to the bottom," where physicians would seek out the jurisdictions with the least oversight. ${ }^{88}$ A reciprocity regime for states with substantially equivalent levels of oversight would solve this problem.

States have taken modest efforts to minimize the burden of securing multiple state licenses. A majority of states offer a consultation exception that allows out-of-state licensed doctors to practice in very limited situations without the specific state's license. ${ }^{89}$ This exception allows out-of-state licensed doctors to consult on patients provided that they work with or offer services at the request of an in-state doctor..$^{90}$ This exception typically requires consultations to be infrequent or that the in-state doctors make the final medical decisions. ${ }^{91}$ These rules essentially require doctor redundancy. Another approach followed by nine states is to have special licenses related to telehealth. ${ }^{92}$ These allow doctors to provide services remotely across state lines, as long as they do not set up a physical office in the state..$^{93}$

The Interstate Medical Licensure Compact ("IMLC" or "Compact"), which began issuing licenses in April 2017, is an agreement between 29 states and the 43 Medical and Osteopathic Boards in those states. ${ }^{94}$ The IMLC creates an expedited process for eligible doctors to apply for licensure in compact states, and it is intended to reduce time and difficulty for doctors seeking licenses in multiple states..$^{95}$ According to the IMLC, "approximately 80 percent of doctors meet the criteria for licensure through the IMLC." 96 Once qualified, the doctor may select any number of Compact states in which they desire to practice. ${ }^{97}$

A compact permits states to maintain agency over their licensing procedures while providing medical professionals an expedited process to gain medical licenses. ${ }^{98}$

\footnotetext{
${ }^{85} I d$.

${ }^{86}$ Gupta \& Sao, supra note 52, at 399-400.

${ }^{87}$ Id.

${ }^{88}$ Marvin F. Filich, Incorporation to Circumvent Usury Laws: Associated Tax Problems and Law, 14 J. CORP. L. 527, 531 (1989).

${ }^{89}$ Ctr. For Connected Health Policy, State Telehealth laws \& Reimbursement POLICIES: A COMPREHENSIVE SCAN OF THE 50 STATES \& DisTRICT OF COLUMBIA 10 (2019) [hereinafter State TElehEAlth LAWS \& REIMBURSEMENT POLICIES]. consultations)

${ }^{90}$ See, e.g., ARK. CODE ANN. § 17-95-206 (2019) (defining such exchanges as "episodic"

${ }^{91}$ See id.

${ }^{92}$ State Telehealth Laws \& Reimbursement Policies, supra note 89 (noting that nine states - Alabama, Louisiana, Maine, Minnesota, New Mexico, Ohio, Oregon, Tennessee, and Texas allow an out-of-state provider to render services via telemedicine in a state where they are not located). ${ }_{93}^{9}$ Paul M. Orbuch, A Western States' Effort to Address Telemedicine Policy Barriers, 73 N.D. L. REV. 35, 47 (1997).

${ }^{94}$ The IMLC, INTERSTATE MED. LICENSURE COMPACT, http://www.imlcc.org/ [https://perma.cc/L64E-BRSN] (last visited Mar. 20,2020). The number of states in the IMLC is current as of April 2020.

${ }^{95} I d$.

${ }^{96} I d$.

${ }^{97} \mathrm{Id}$.

${ }^{98}$ Facts about the IMLCC, INTERSTATE MED. LICENSURE COMPACT, https://imlcc.org/facts-aboutthe-imlcc/ [https://perma.cc/MG7Q-9URV] (last visited Mar. 20, 2020).
} 
These are not, however, cross-border licenses. ${ }^{99}$ The Compact still requires that a medical professional apply for license in each state in which they wish to practice, which is less efficient than automatic reciprocity of a potential uniform law, or a federal solution. ${ }^{100}$ Contrast the doctor IMLC with the Nurse Licensure Compact, which is more like a "multi-state license similar to a driver's license, where the license is recognized in the home state and other compact member states," without making further applications. ${ }^{101}$

Notwithstanding these avenues of reform, many states continue to restrict healthcare providers from practicing telemedicine by requiring a full license in the state of service. ${ }^{102}$ These states often define "the practice of medicine broadly to include phone calls, e-mails, and on-line discussions, circumscribe[ing] the use of the new technology." 103 To the extent that these state licensing laws are designed to favor local providers, they may arguably be subject to challenge under the dormant commerce clause of the U.S. Constitution, ${ }^{104}$ or under federal antitrust laws. ${ }^{105}$ Regardless, Congress should consider affirmatively preempting them as hindrances to interstate commerce and federal spending, such as Medicare. Likewise, Congress preempted state doctrines around corporate practice of medicine, to the extent that they interfere with the work of Health Maintenance Organizations ("HMOs"). ${ }^{106}$

Similar to when and how a healthcare relationship should be established, states may claim that strict licensure laws improve standardization and quality of care, ${ }^{107}$ but if the benefit is slim, then it may not offset the chilling effect of the on cross-border practice, and hence, provider participation and patient access. In fact, state licensure laws do not vary substantially, and a more ambitious alignment seems to be a promising path forward. ${ }^{108}$

\section{REIMBURSEMENT OF COSTS}

In this section, we describe current approaches by insurers, including Medicare, Medicaid, and private carriers, to reimburse for telehealth services. We discuss related state laws, and suggest how to optimize reimbursement for greater telehealth adoption.

On the private payor front, 40 states and the District of Columbia have laws governing reimbursement for telehealth. ${ }^{109}$ These laws either require coverage parity, which ensures that a service is reimbursed if provided through telehealth, or payment

${ }^{99}$ See Caleb Zimmerschied, Cross-state Licensing Process Now Live in 8 States, AM. MED. ASS'N (May 8, 2017), https://www .ama-assn.org/practice-management/digital/cross-state-licensing-process-nowlive-8-states [https://perma.cc/LJ5U-RCQK].

${ }^{100}$ See Ellen R. Cohn et al., Resolving Barriers to Licensure Portability for Telerehabilitation Professionals, 3 INT'L J. TELEREHABILITATION 31, 31 (2011).

101NAT'L CONFERENCE OF State Legislators, TelehEalth POLICY TRENDS AND CONSIDERATIONS 17 (2015).

102 See id. at 16.

${ }^{103}$ Carl F. Ameringer, State-Based Licensure of Telemedicine: The Need for Uniformity but Not a National Scheme, 14 J. HEALTH CARE L. \& POL'Y 55, 58-59 (2011).

${ }^{104}$ See Gupta \& Sao, supra note 52, at 417-27 (making this argument); see also Ass'n for Accessible Meds. v. Frosh, 887 F.3d 664, 670 (4th Cir. 2018) (finding that a pharmaceutical pricing statute violated the dormant commerce clause).

${ }^{105}$ N.C. State Bd. of Dental Exam'rs v. FTC, 574 U.S. 494, 506-07 (2015) (no antitrust immunity for state professional boards unless directed by the state).

10642 U.S.C. $\$ 300 \mathrm{e}-10$ (2018).

${ }^{107}$ See Humayun J. Chaudhry et al., Commentary, Maintenance of Licensure: Protecting the Public, Promoting Quality Health Care, 96 J. MED. REG. 13, 13-14 (2010).

10842 U.S.C. $\$ 300 \mathrm{e}-10$.

${ }^{109}$ Ctr. For CONNECted Health Policy, Sate Telehealth Laws \& Reimbursement POLICIES, 9-10 (2019). 
parity, which ensures that reimbursement is at the same rate as when care is delivered in-person. ${ }^{110}$ If the policy goal is to increase use of telehealth, then payment parity can reassure doctors that telehealth will not undercut their revenues. However, payment parity laws can defeat the policy advantage of telehealth to reduce costs. ${ }^{111}$

Because the majority of states have private-payer reimbursement laws of some sort, the current practice is to amend a law to expand its applicability to additional specialties.Minnesota, for example, did this when it expanded its private-payer law to cover dental coverage, while Utah's expansion singles out telepsychiatry services, ${ }^{112}$ and Washington allows telemedicine to be offered from "any location determined by the individual receiving the service." 113 It is important to question whether these privatepayer laws are necessary to expand reimbursement efforts given increasing market demand. A Milbank report documented interviews in six states that did not have parity in payment laws, yet found that almost all private health insurers covered telehealth services and paid the same rate as in-person services. ${ }^{114}$

The aforementioned expansion of MA plans to cover telehealth could be an excellent natural experiment to compare before and after 2020. The clear implementation date could determine whether and how much reimbursement changes are improving overall utilization, access to care, better health outcomes, and lower costs when compared to the traditional Medicare population, in essence the control group. Comparisons between states may also be striking as most MA enrollees, forty percent, reside in six states (Florida, Hawaii, Minnesota, Oregon, Pennsylvania, and Wisconsin) and Puerto Rico, and, by contrast, rural states have lower rates of MA enrollees. ${ }^{115}$

MA's expansion into the telehealth may create additional market pressure for private insurers (who often also administer MA plans) to voluntarily reimburse for telehealth services. Traditional Medicare may follow the pathway that MA is starting with a bipartisan bill that was reintroduced on October 30, 2019 entitled Creating Opportunities Now for Necessary and Effective Care Technologies "CONNECT" for Health Act, which is currently pending in the Senate Finance Committee. ${ }^{116}$ This bill would reduce geographic and site-specific requirements for traditional Medicare so that these beneficiaries would also receive telehealth delivered care directly in their homes. ${ }^{117}$ This pending legislation could make an enormous impact on telehealth utilization nationwide where the pool of patients would surge to nearly 60 million people.

The MA move may also influence Medicaid, especially as the largest payor for long-term care in America. There are over six million older adults on Medicaid who have both Medicare and Medicaid coverage (aka "dual-eligibility"), and this is largely attributable to them going through their savings paying for some form of long-term care. ${ }^{118}$

${ }^{110}$ See Matthew Loughran, Telemedicine Reimbursement Laws Challenge Insurers and Providers Alike (Oct. 17, 2017) (8:30 AM), https://news.bloomberglaw.com/pharma-and-life-sciences/telemedicinereimbursement-laws-challenge-insurers-and-providers-alike [https://perma.cc/9MWH-RPWR].

${ }^{111}$ See Katherine Restrepo, The Case Against Telemedicine Parity Laws, JOHN LOCKE Found. (Jan. 15, 2018), https://www.johnlocke.org/research/telemedicine/ [https://perma.cc/M48D-MK2C] ("Telemedicine parity laws force private insurance carriers to cover treatment via telemedicine that is otherwise covered during an in-office visit.").

${ }^{112}$ STATE TELEHEALTH LAWS \& REIMBURSEMENT POLICIES, supra note 89, at 217, 390-91.

${ }^{113}$ WASH. REV. CODE $§ 48.43 .735(3)(\mathrm{g})(2020)$.

114TELEHEALTH PRIVATE PAYER LAWS, supra note 50, at 14

115 Jacobson et al., supra note 40.

${ }^{116}$ Creating Opportunities Now for Necessary and Effective Care Technologies (CONNECT) for Health Act of 2019, S. 2741, 116th Cong. (introduced in Senate, Oct. 30. 2019).

${ }^{117} I d$.

${ }^{118}$ See Julia Paradise et al., Medicaid at 50, KAISER FAMILY FOUND. (May 6, 2015), https://www.kff.org/report-section/medicaid-at-50-the-elderly/ [https://perma.cc/J8VU-EC3W]. 
In an effort to extend personal finances, a phenomenon of "aging in place" is gaining primacy as the preferred long-term care model, rather than a nursing home or institutional setting. ${ }^{119}$

Telehealth coverage and reimbursement in state Medicaid programs vary considerably. Almost all states (49) and the District of Columbia have some coverage for telehealth, and nearly all reimburse for live video telehealth. ${ }^{120}$ Some state Medicaid programs impose restrictions such as limits on the sort of facilities where telehealth care can be received, by what type of healthcare provider, and geographic restrictions. ${ }^{121}$ As of 2016, eight state Medicaid programs reimbursed for telehealth under their home health services, but this number more than doubled to 19 states by $2019 .{ }^{122}$ Patients are eligible for these Medicaid services if they have two or more chronic conditions, one chronic condition and are at risk for a second, or have one serious and persistent mental health condition. ${ }^{123}$ Given the prevalence for chronic conditions and mental health among older adults, as previously discussed, many will be able to meet the eligibility requirement. ${ }^{124}$

States are removing some of these restrictions, for instance, the majority of state Medicaid programs no longer have rural requirements that must be met for telehealth reimbursement. ${ }^{125}$ Additionally, a number of states are demonstrating innovative efforts with funding support from the federal government, namely through grants and waivers for home health programs. ${ }^{126}$ With the consent of the U.S. Department of Health and Human Services, Alabama, Iowa, Maine, New York, Ohio, and West Virginia have all used state plan amendments that include telehealth coverage in their home health proposals. ${ }^{127}$ Similarly, Kansas, Pennsylvania, and South Carolina have used waivers to cover remote patient monitoring for long-term care services. ${ }^{128}$

Across all these domains of insurance, the quick expansion of telehealth coverage may be worrisome if it forces patients who would otherwise prefer an inperson visit to only have access to care via telehealth. One option to help curtail this issue is for insurance regulators to require that insurers maintain an in-person option for members. Nonetheless, such insurance mandates may wreak inefficiency, if they do not reflect consumer preferences.

\section{CONCLUSION}

Telehealth is increasingly important to the future practice of medicine, but poses a unique set of challenges for state lawmakers as they attempt to navigate interstate practice. Additionally, state and federal lawmakers are being confronted with how to

119 Tara Sklar \& Rachel Zuraw, Preparing to Age in Place: The Role of Medicaid Waivers in Elder Abuse Prevention, 28 AnNALS HEALTH L. \& SCI. 195, 195 (2019).

${ }^{120}$ See NAT'L CONFERENCE OF STATE LEGISLATURES, supra note 101, at 13. See generally STATE TELEHEALTH LAWS \& REIMBURSEMENT POLICIES, supra note 89, (surveying the telemedicine landscape across all 50 states among several metrics).

${ }^{121}$ See id.

122NAT'L CONFERENCE OF STATE LEGISLATORS, supra note 101, at 12.

${ }^{123}$ Health Homes, MEDICAID.GOV, https://www.medicaid.gov/medicaid/long-term-servicessupports/health-homes/index.html [https://perma.cc/SL85-Y562] (last visited Mar. 20, 2020).

${ }^{124}$ See discussion supra Part II.

${ }^{125}$ NAT'L CONFERENCE OF STATE LEGISLATORS, supra note 101, at 12.

${ }^{126}$ See InSt. OF MED., COMM. ON Evaluating CliniCAL APPliCATIONS of Telemedicine, TElemedicine: A GUIDE TO ASSESSING TELECOMMUNICATIONS FOR HEALTH CARE 229 (1996).

${ }^{127}$ See 50-STATE SURVEY: PATIENT-PHYSICIAN RELATIONSHIP VIA TELEMED, supra note 68.

${ }^{128}$ See id. 
provide high-quality, affordable care for an aging population that will live for an average of two decades with multiple chronic conditions. ${ }^{129}$

It is clear that law plays a substantial role in how quickly telehealth operators can achieve the scale necessary to provide care for an older population in their homes. Fortunately, state licensure laws are actively reducing some of the administrative burdens that had limited cross-border practice with support for an interstate compact. ${ }^{130}$ But much more can be done on this front; the fragmentation of state-based licensure likely does not promote quality or efficiency compared to a unified or seamless system. Furthermore, the CMS rule to allow MA plans to reimburse for care received in the home is an essential move for telehealth to suddenly reach a much broader and older population where utilization has been disproportionately low compared to other age groups. ${ }^{131}$ This federal-private insurer effort combined with the work already underway via state Medicaid programs should continue nationwide growth for telehealth adoption.

An area that continues to remain variable across states is the establishment of a healthcare relationship. The position of the AMA and the states that follow it reflect a presumption that in-person interactions should remain the baseline for healthcare standards. Also discussed, to require an in-person visit for patients who cannot leave their homes without substantial difficulty, and for conditions where the standard of care would not require a physical exam, seems unnecessarily onerous and costly for all parties. A more flexible, forward-looking approach would be for lawmakers to allow alternatives or exceptions that recognize telehealth's unique capabilities and the patients that would most benefit from this form of care.

${ }^{129}$ See NAT'L COUNCIL ON AGING, supra note 27.

${ }^{130}$ Zimmerschied, supra note 99.

${ }^{131}$ See CMS Finalizes Polices to Bring Telehealth to Medicare Advantage, supra note 38. 